\title{
Article \\ Application of $\beta$-Glucosidase in a Biphasic System for the Efficient Conversion of Polydatin to Resveratrol
}

\author{
Jie Zhou ${ }^{1}$, Meng Liang ${ }^{1}$, Yu Lin ${ }^{1}$, Hao Pang ${ }^{2, *}$, Yutuo Wei ${ }^{1}$, Ribo Huang ${ }^{1}$ and Liqin Du ${ }^{1, *}$ \\ 1 State Key Laboratory for Conservation and Utilization of Subtropical Agro-Bioresources, Guangxi Research \\ Center for Microbial and Enzymatic Technology, College of Life Science and Technology, Guangxi University, \\ Daxue Road No. 100, Nanning 530005, China; zhoujie@gxu.edu.cn (J.Z.); 1m9267@163.com (M.L.); \\ wslinyu2022@163.com (Y.L.); weiyutuo@gxu.edu.cn (Y.W.); guruace@163.com (R.H.) \\ 2 Guangxi Key Laboratory of Bio-Refinery, National Engineering Research Center for Non-Food Biorefinery, \\ State Key Laboratory of Non-Food Biomass and Enzyme Technology, Guangxi Academy of Sciences, \\ Daling Road No. 98, Nanning 530007, China \\ * Correspondence: panghouse@126.com (H.P.); duliqin@gxu.edu.cn (L.D.); Tel.: +86-771-2503987 (H.P.); \\ +86-771-3235706 (L.D.)
}

check for updates

Citation: Zhou, J.; Liang, M.; Lin, Y.; Pang, H.; Wei, Y.; Huang, R.; Du, L. Application of $\beta$-Glucosidase in a Biphasic System for the Efficient Conversion of Polydatin to Resveratrol. Molecules 2022, 27, 1514. https://doi.org/10.3390/ molecules27051514

Academic Editor: Louis

Pergaud Sandjo

Received: 28 January 2022

Accepted: 22 February 2022

Published: 23 February 2022

Publisher's Note: MDPI stays neutral with regard to jurisdictional claims in published maps and institutional affiliations.

Copyright: () 2022 by the authors Licensee MDPI, Basel, Switzerland. This article is an open access article distributed under the terms and conditions of the Creative Commons Attribution (CC BY) license (https:// creativecommons.org/licenses/by/ $4.0 /)$.

\begin{abstract}
Resveratrol, an ingredient of traditional Chinese medicine, has beneficial effects on human health and huge potential for application in modern medicine. Polydatin is extracted from plants and then deglycosylated into resveratrol; enzymatic methods are preferred for this reaction. In this study, a $\beta$-D-glucosidase from Sphingomonas showed high efficiency in transforming polydatin into resveratrol and was tolerant toward organic solvents. Applying this enzyme in a biphasic transformation system resulted in $95.3 \%$ conversion of $20 \%$ concentration crude polydatin to resveratrol in $4 \mathrm{~h}$. We thus report a new method for high-efficiency, clean production of resveratrol.
\end{abstract}

Keywords: resveratrol; polydatin; $\beta$-D-Glucosidase; biphasic enzymatic transformation

\section{Introduction}

Stilbenes are secondary metabolites of plants. Because of their potential effects in ameliorating human health [1-3], increasing attention has been paid to their synthesis and molecular modes of action. Among the many stilbenes, resveratrol (trans-3,5,4 trihydroxystilbene) is the most prominent in medical applications. Resveratrol is believed to have anti-inflammatory [4], anti-aging [5] and cardioprotective effects [6], and it has been applied as nutritional supplement in health products and cosmetics products [7]. Resveratrol is found in many plants such as vegetables [8] and fruits [9-12]. The root of Polygonum cuspidatum was found to be the richest source of resveratrol [13]. Compared with resveratrol synthesized by chemical synthesis (de novo synthesis), resveratrol produced by the P. cuspidatum extraction process is more economical and has been widely used.

In plants, resveratrol is present as a glycoside, polydatin, in which a glucoside group bound to the C-3 position substitutes for a hydroxyl group (Figure 1). However, polydatin has lower bioavailability than resveratrol, and it is shown that human intestinal cell absorb polydatin with greater difficulty and more slowly than resveratrol [14,15]. Thus, deglycosylation of polydatin is important to obtain the active resveratrol. In recent years, many new methods have been developed for producing resveratrol from polydatin [16-21]. Bioconversion is a promising approach because of its high conversion efficiency and environmental friendliness compared with conventional chemical synthesis and hydrolysis methods. It is reported that diverse fungi show great potential in converting polydatin to resveratrol, including Aspergillus niger [22], Rhizopus sp. T-34 [23] and other fungi [24]. However, 5-8 days are generally needed to attain high-level conversion. 


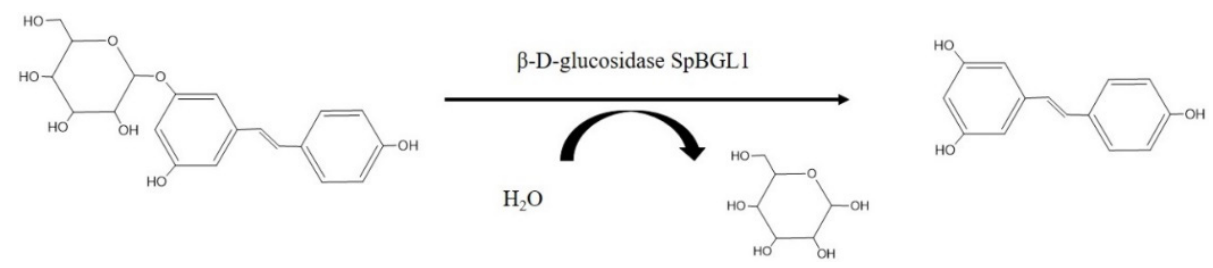

Figure 1. The conversion of polydatin into resveratrol by SpBGL1, a $\beta$-D-glucosidase from Sphingomonas sp. ATCC31555. One molecule of polydatin is hydrolyzed into one molecule of glucose and one molecule of resveratrol.

Polydatin can be converted to resveratrol by $\beta$-D-glucosidases. Direct enzymatic conversion of polydatin to resveratrol should be more efficient and less time consuming than microbial whole cell conversion because the reaction conditions can be set to match the optimal conditions for catalysis by the enzyme. However, for glycoside aromatic compounds containing aglycones, the large aglycone spatially blocks the contact of the enzyme to the glycosidic bond. It is rare that an enzyme has the ability to hydrolyze this linkage between aryl aglycones and glycosyl group [25,26]. Chen et al. [27] reported that a piceid- $\beta$-D-glucosidase cloned from Aspergillus showed preferable characteristics and high overall conversion efficiency in converting polydatin to resveratrol. Bacteria are considered to be more suitable for the biotransformation of polydatin than mold, but the enzyme suitable for the transformation of polydatin screened from bacteria is lacking [17].

The poor aqueous solubility and good organic solvent solubility of polydatin and resveratrol result in another complication in both enzymatic and whole-cell conversions. Generally, conversion reactions are carried out in aqueous solutions with little or no organic solvent $[19,21]$. Subsequently, the substrate and the product are mixed and precipitated, and the product must be recovered using organic solvent extraction [19]. Unavoidably, the final product will be contaminated by substrate.

To overcome the conversion problem of resveratrol, a biphase transformation system was set up using a $\beta$-D-glucosidase, named SpBGL1, from Sphingomonas sp. ATCC31555. This enzyme showed preferable characteristics in converting polydatin to resveratrol and was highly tolerant toward organic solvents. This biphase biotransformation system resulted in good conversion of polydatin to resveratrol and high product purity.

\section{Results}

\subsection{Enzymatic Properties of $\beta$-D-Glucosidase SpBGL1}

A putative glycoside hydrolase family (GH) $3 \beta$-D-glucosidase-encoding gene (WP_019370396.1) was identified in the genome of Sphingomonas sp. ATCC 31555 by sequence analysis. The product of this gene was named SpBGL1. The deduced protein has 802 amino acids (Figure 2); the predicted molecular mass and pI were calculated as $86.911 \mathrm{kDa}$ and 6.76, respectively by using Geneious 11.0.5.

SpBGL1 hydrolyzed $p$ NPG (4-Nitrophenyl- $\beta$-D-glucopyranoside), proving that this enzyme is a $\beta$-D-glucosidase. When using $p N P G$ as the substrate, the enzyme showed its highest hydrolytic activity at $\mathrm{pH} 5.5$ at $45^{\circ} \mathrm{C}$; the $\mathrm{K}_{\mathrm{m}}$ and $\mathrm{V}_{\max }$ values were $13.09 \pm 3.43 \mathrm{mM}$ and $5.817 \pm 0.59 \mu \mathrm{mol} / \mathrm{min}$, respectively.

SpBGL1 showed high tolerance to glucose. The tolerance was glucose-concentration dependent. SpBGL1 maintained 55\% relative activity in the presence of $1 \mathrm{M}$ glucose, while in the presence of $3 \mathrm{M}$ glucose, $28 \%$ relative activity was maintained. The $\mathrm{K}_{\mathrm{i}}$ value calculated using the SNLR (simultaneous nonlinear regression fit) method was $60.9 \pm 0.45$ (Figure 3). 


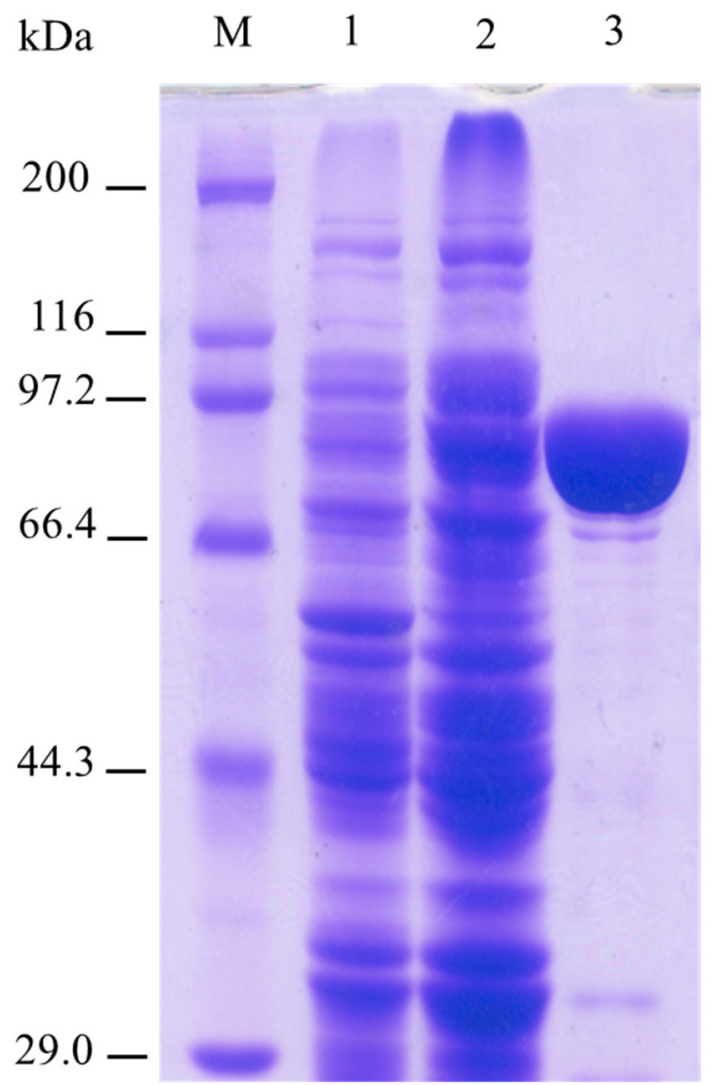

Figure 2. SDS polyacrylamide gel electrophoresis analysis of purified recombinant SpBGL1. M, molecular weight marker (Takara, Protein Molecuar Weight Marker (Broad), D532A); 1—crude protein extraction of JM109 harboring pQE30; 2-crude protein extraction of JM109 harboring pQESpBGL1; 3-purified SpBGL1.

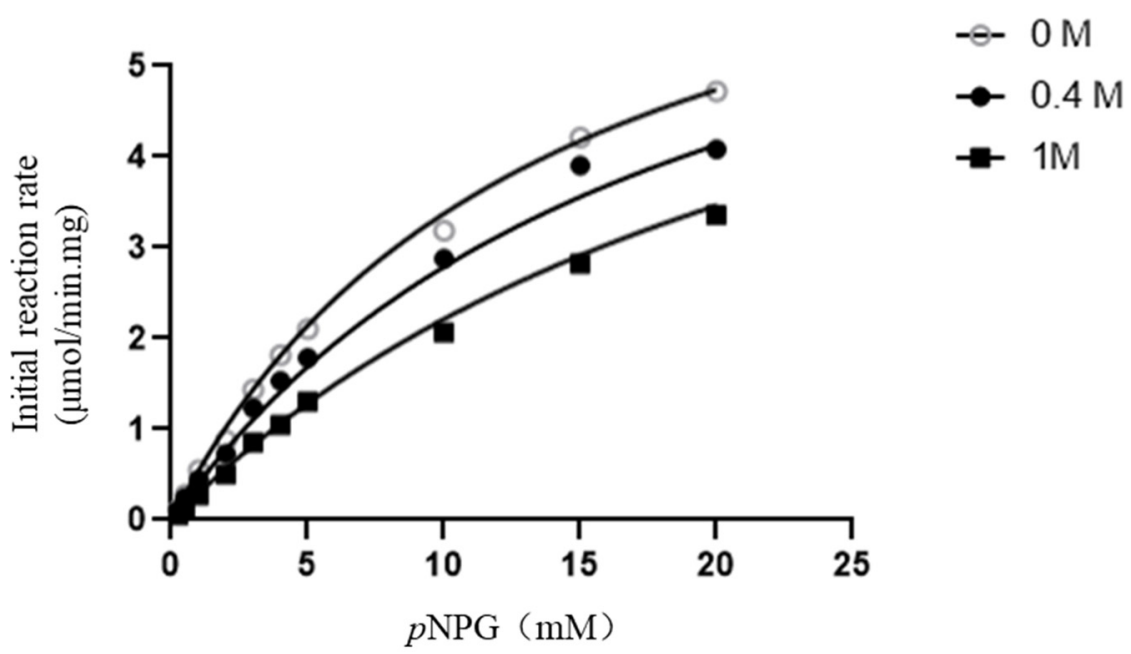

Figure 3. The determination of glucose inhibition constant using SNLR method.

Table 1 was determined (Table 1). In the optimum reaction conditions, SpBGL1 showed good efficacy in hydrolyzing epimedin A, icariin, daidzin and polydatin. 
Table 1. Substrate profile of SpBGL1.

\begin{tabular}{cc}
\hline Substrate & Activity \\
\hline Polydatin & + \\
Daidzin & + \\
Glycitin & + \\
Genistin & + \\
Icariin & + \\
Epimedin A & + \\
Epimedin B & + \\
Epimedin C & + \\
Rebaudioside A & - \\
Stevioside & - \\
\hline
\end{tabular}

Reaction by SpBGL1 was performed for $30 \mathrm{~min}$.

The tolerance of SpBGL1 to diverse organic compounds was investigated. SpBGL1 showed good tolerance to methanol and ethanol; relative enzyme activity of $60.1 \%$ and $90.9 \%$ was maintained in the presence of $15 \%(v / v)$ methanol and ethanol, respectively, and $69.1 \%$ relative activity was maintained in $20 \%(v / v)$ ethanol (Figure 4$)$. Furthermore, Tween $80(5 \%, v / v)$ showed negligible inhibition of the activity of SpBGL1, and Triton X-100 $(1 \%, v / v), \beta$-mercaptoethanol $(1 \%, v / v)$ and imidazole $(10 \mathrm{mM})$ resulted in slight enhancement of the activity (Figure 5).

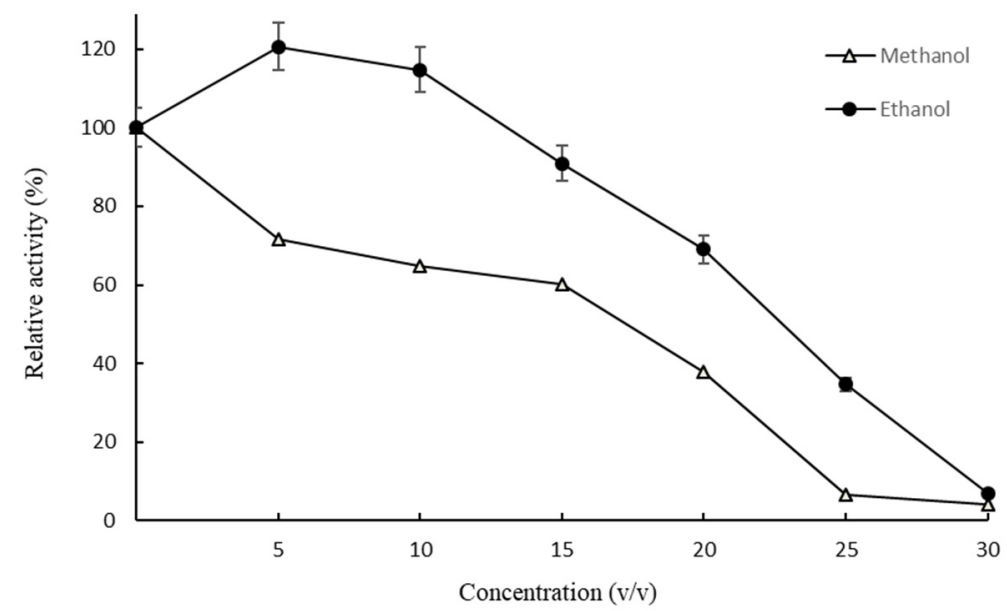

Figure 4. The effects of methanol and ethanol on the enzymatic activity of SpBGL1 with $p$ NPG as substrate. The relative activity of the enzyme is plotted against the concentration of methanol or ethanol in the reaction solution. Each value in the figure represents the mean \pm standard deviation $(n=3)$. 


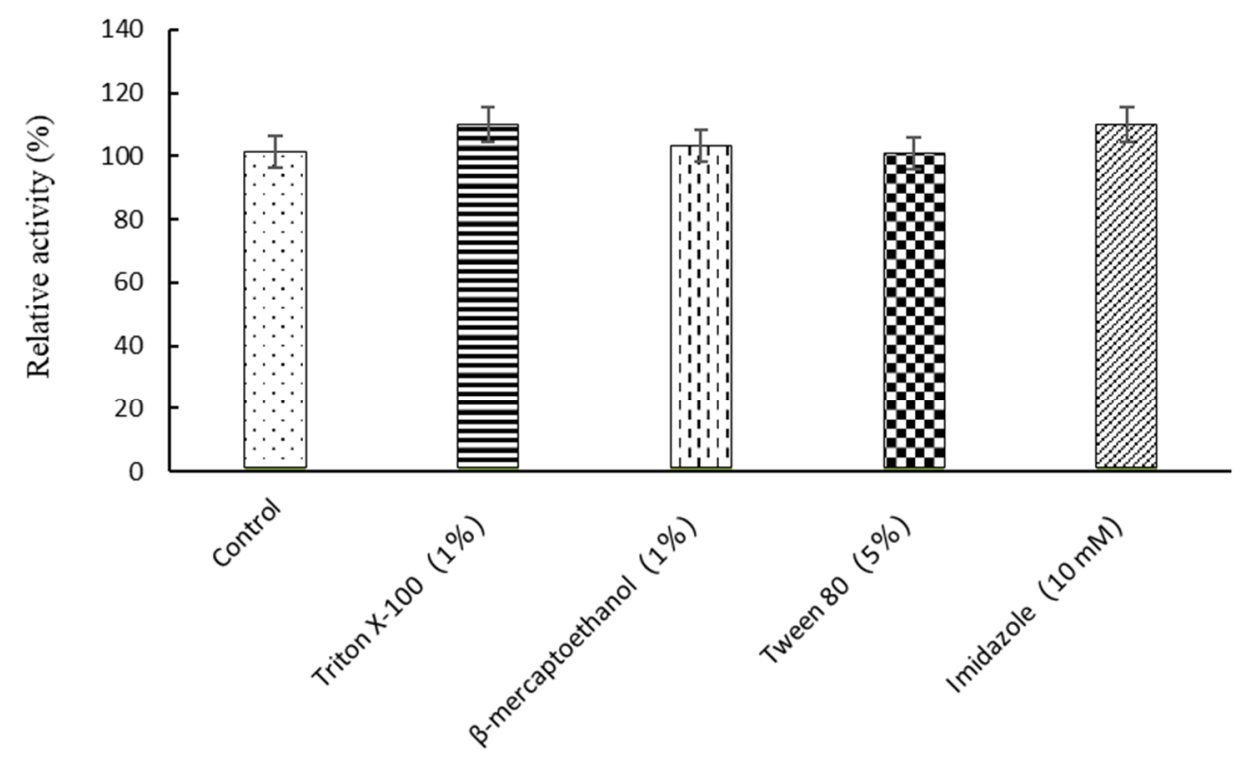

Figure 5. The relative enzymatic activity of SpBGL1 with $p$ NPG as substrate in the presence of Triton X-100, $\beta$-mercaptoethanol, Tween 80 , or imidazole. The experiments were triplicated, and the error bars represent the standard deviation.

\subsection{Optimal Reaction Conditions for Hydrolyzing Polydatin}

Assays were carried out to determine the optimal reaction temperature and $\mathrm{pH}$ for conversion of polydatin into resveratrol by SpBGL1. The relative enzymatic activity of SpBGL1 was measured at $40{ }^{\circ} \mathrm{C}$ for $20 \mathrm{~min}$ at $\mathrm{pH}$ values ranging from 4.5 to 7 (interval 0.5). The maximum conversion ratio, $67.4 \%$, was observed at $\mathrm{pH} 6.0$ (Figure $6 \mathrm{~A}$ ). 


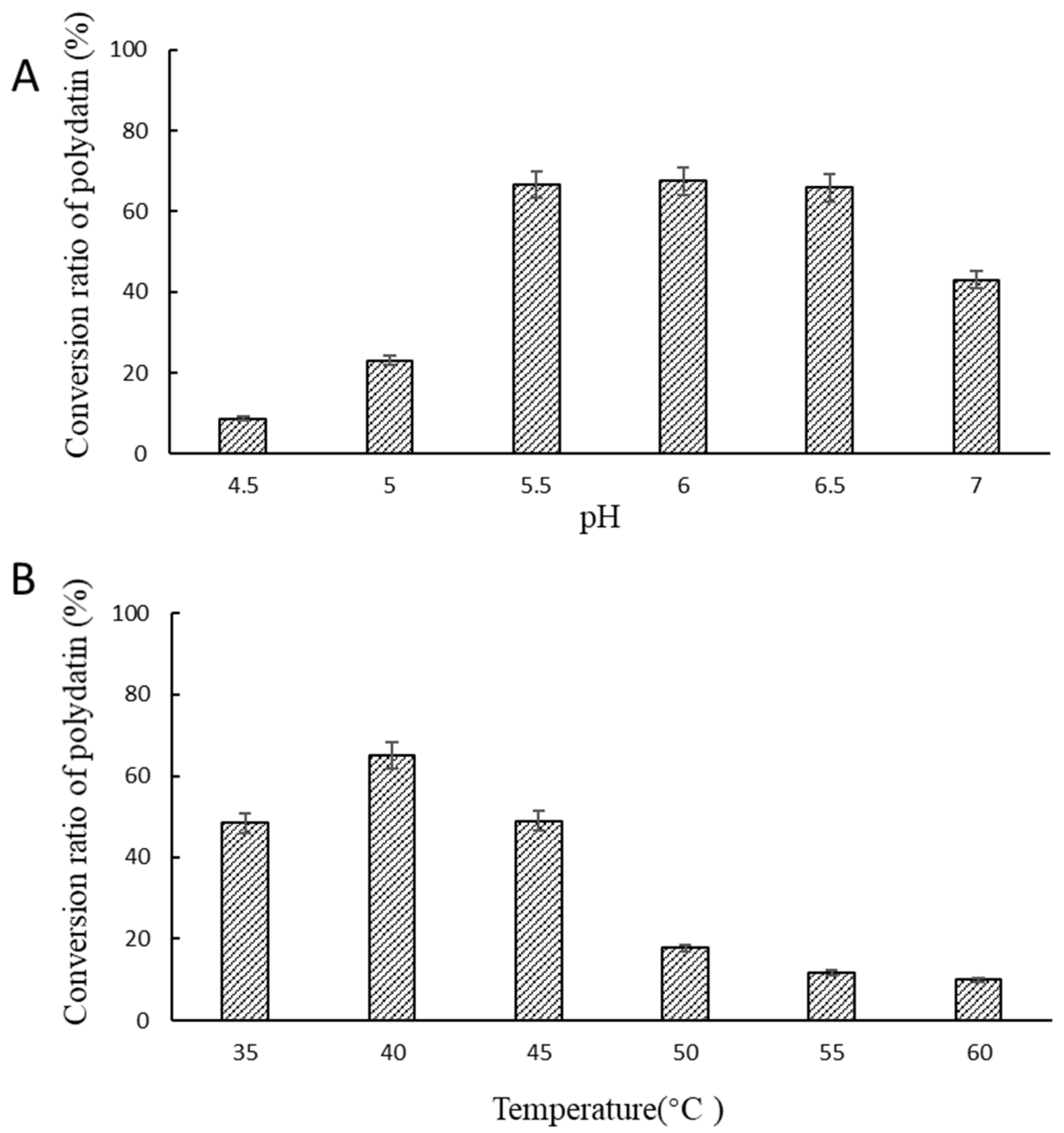

Figure 6. Effect of (A) $\mathrm{pH}$ and (B) temperature on the enzymatic activity of SpBGL1 in converting polydatin to resveratrol. The effect of $\mathrm{pH}$ was determined by incubating the enzyme with the substrate at $37{ }^{\circ} \mathrm{C}$ at different $\mathrm{pH}$ values for $20 \mathrm{~min}$; the effect of temperature was determined at pH 6.0 for $20 \mathrm{~min}$.

To determine the effect of temperature at the optimal $\mathrm{pH}$, enzymatic conversions were carried out at $35,40,45,50,55$ and $60{ }^{\circ} \mathrm{C}$ and $\mathrm{pH} 6.0$ for $30 \mathrm{~min}$. The maximum conversion ratio was observed at $40^{\circ} \mathrm{C}$. At $60^{\circ} \mathrm{C}$, only $10.07 \%$ of the polydatin was transformed into resveratrol (Figure 6B).

\subsection{Comparison of Uniaphase and Biphase Enzymatic Conversion for Polydatin Hydrolysis}

Two different enzymatic transformation systems were set up and compared for their effectiveness in converting polydatin to resveratrol (Figure 7). The reactions in both the uniphase and the biphase systems were carried out on polydatin extract (20\% purity), final concentration $20 \mathrm{~g} / \mathrm{L}$, at $40^{\circ} \mathrm{C}$ and $\mathrm{pH}$ 6.0. As shown in Figure 7, in the biphase system, the color of the organic phase darkened as the reaction took place, and the amount of crude polydatin decreased dramatically (Figure 8A). The amount of crude polydatin did not show an observable decrease (by eye) in the uniphase conversion system (Figure $8 \mathrm{~B}$ ). The reaction solutions in both systems were analyzed by high-performance liquid chromatography (HPLC) at different time points to determine the overall conversion ratio (Figure 9). At all reaction time points, the conversion ratio in the biphase system were significantly higher than those in the uniphase system. In the biphase system, the overall conversion ratio 
reached $95.25 \%$ in $4 \mathrm{~h}$, whereas the conversion ratio reached only $85.74 \%$ at $6 \mathrm{~h}$ in the uniphase system (Figure 10).

A

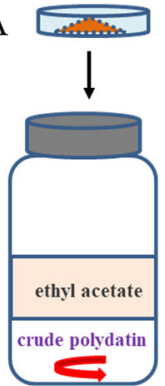

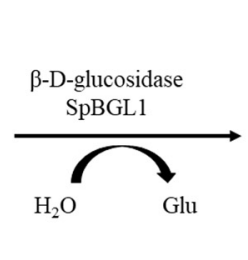

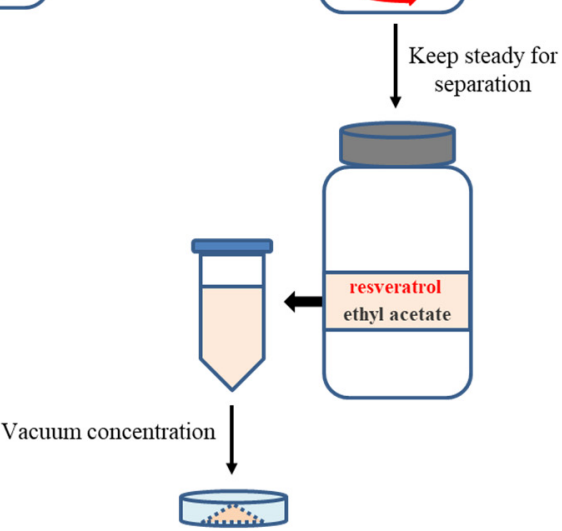

B

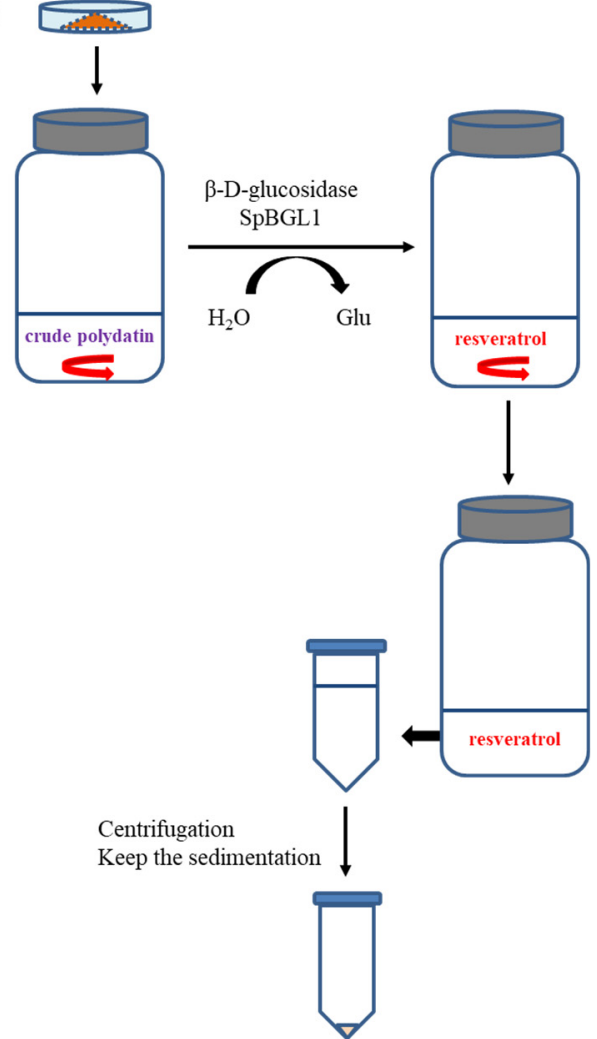

Recover the sedimentation in 10 volumes of $80 \%$ methanol

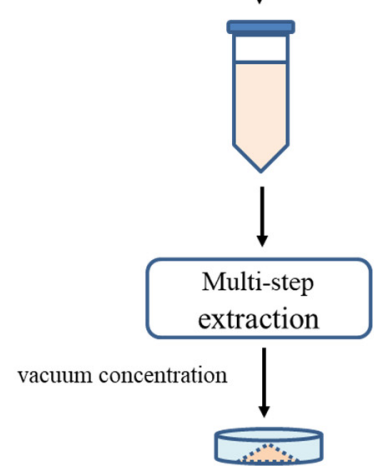

Figure 7. Schematic presentation of the biphase (A) and uniphase (B) conversion systems set up in this study and the major procedure of using these systems to convert polydatin into resveratrol. In the biphase system, the conversion took place in the aqueous phase, and the resulting resveratrol continuously dissolved in the organic phase. Resveratrol can be extracted directly from the organic phase by vacuum concentration. In the uniphase conversion system, because of the low solubility of resveratrol in aqueous solution, the product must first be separated from the aqueous solution by centrifugation, then recovered in $80 \%$ ethanol. This solution is then passed through an overnight multistep extraction procedure before finally being vacuum concentrated. 
A

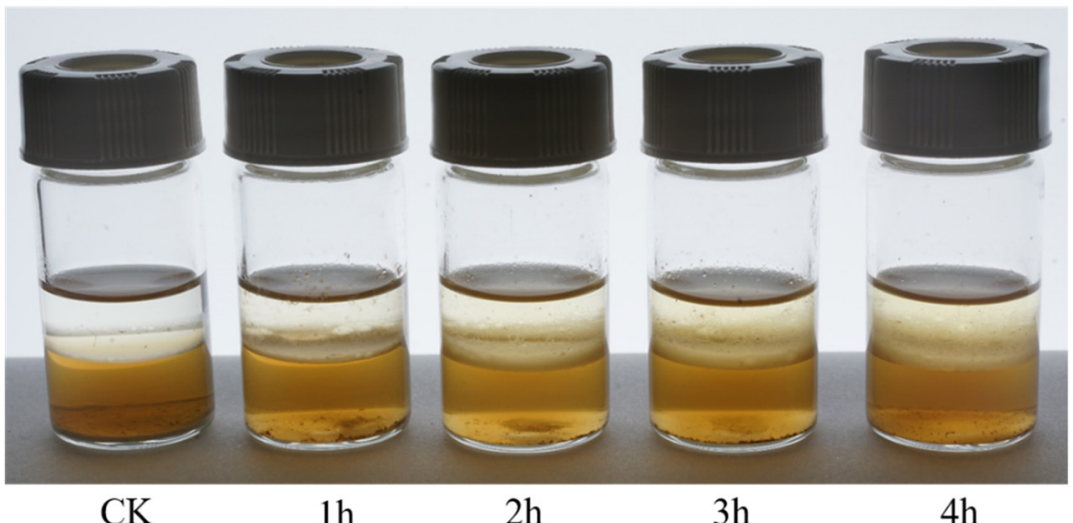

B

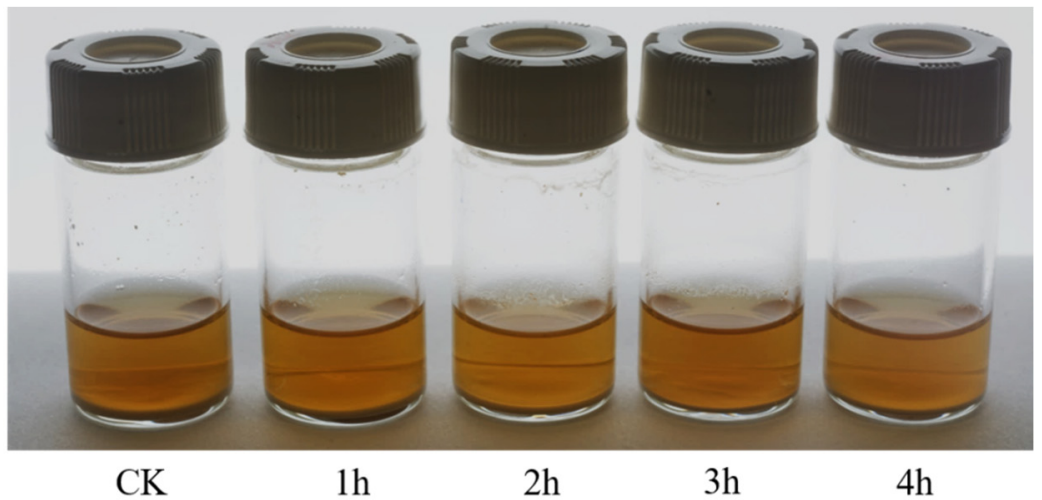

Figure 8. Conversion of polydatin into resveratrol by SpBGL1 in the biphase (A) and uniphase (B) conversion systems. Pictures were taken every hour after stopping agitation.

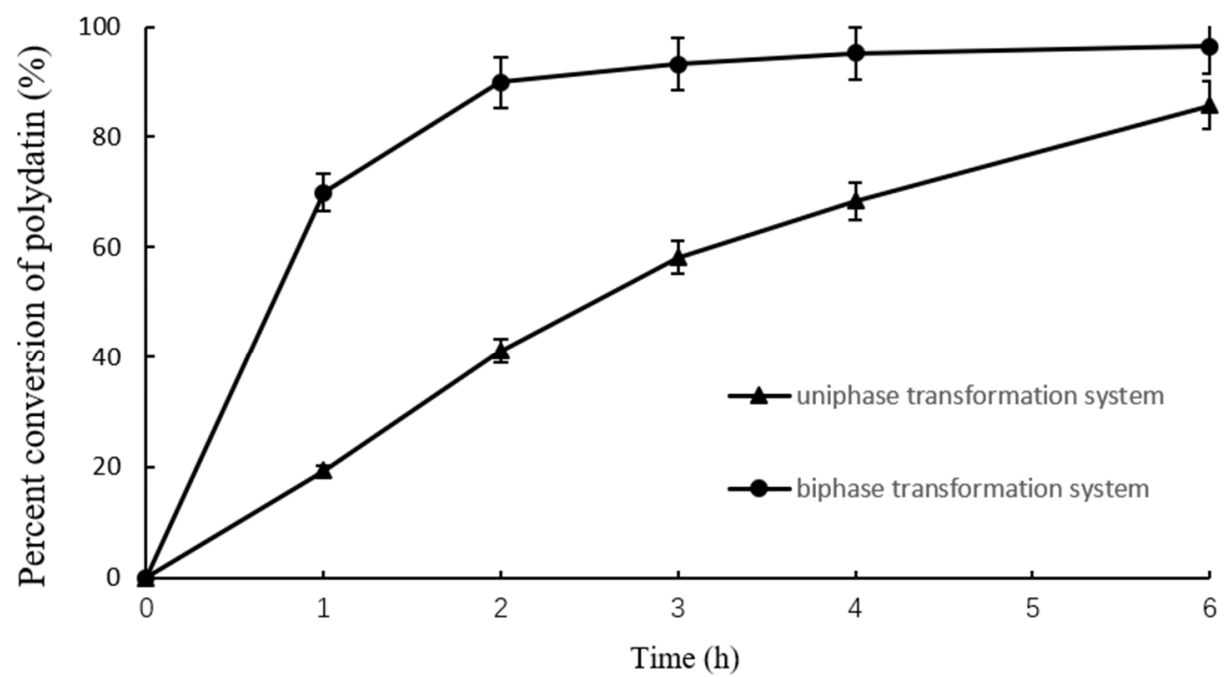

Figure 9. Effect of reaction time on conversion of polydatin by SpBGL1 in the uniphase and biphase conversion systems. 
A
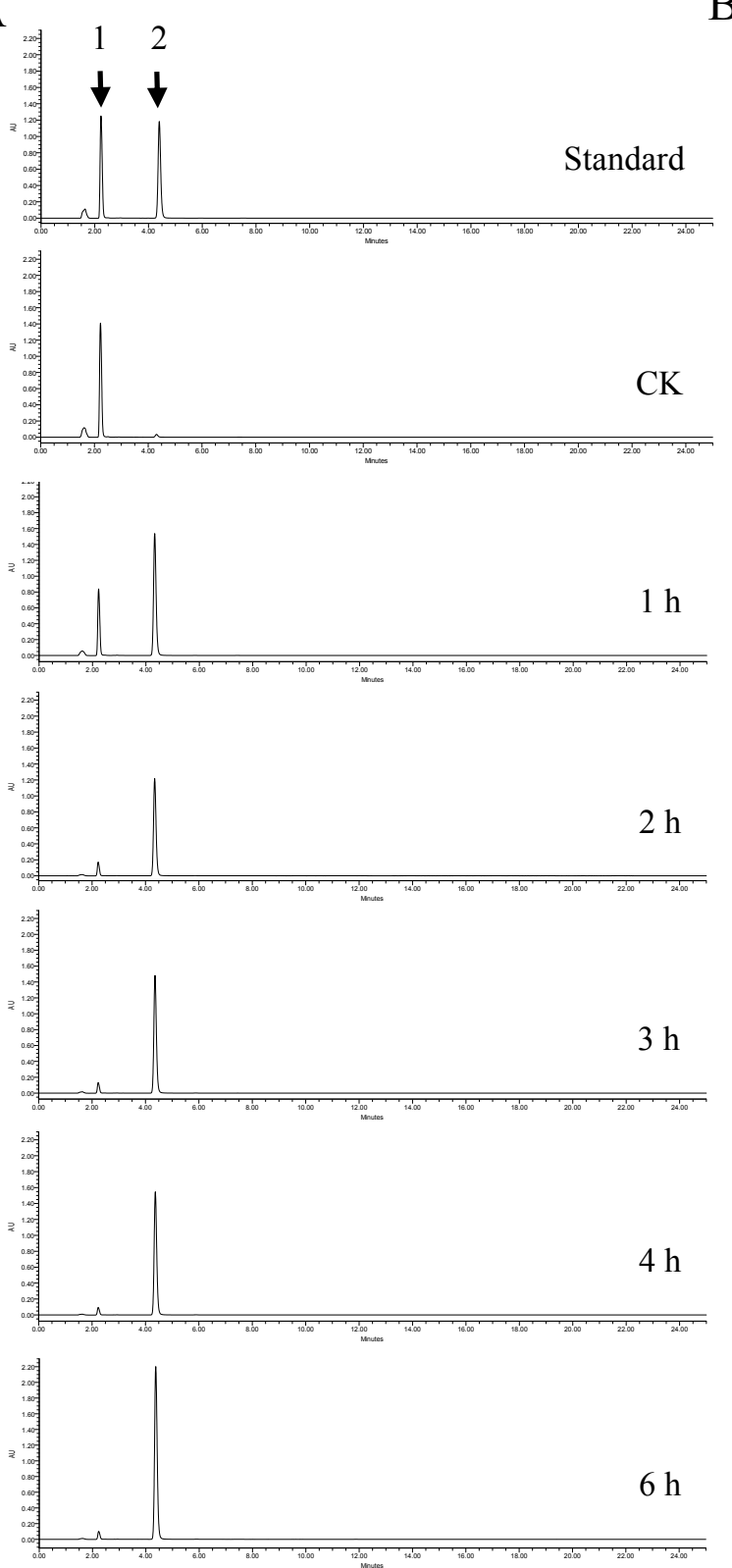

B
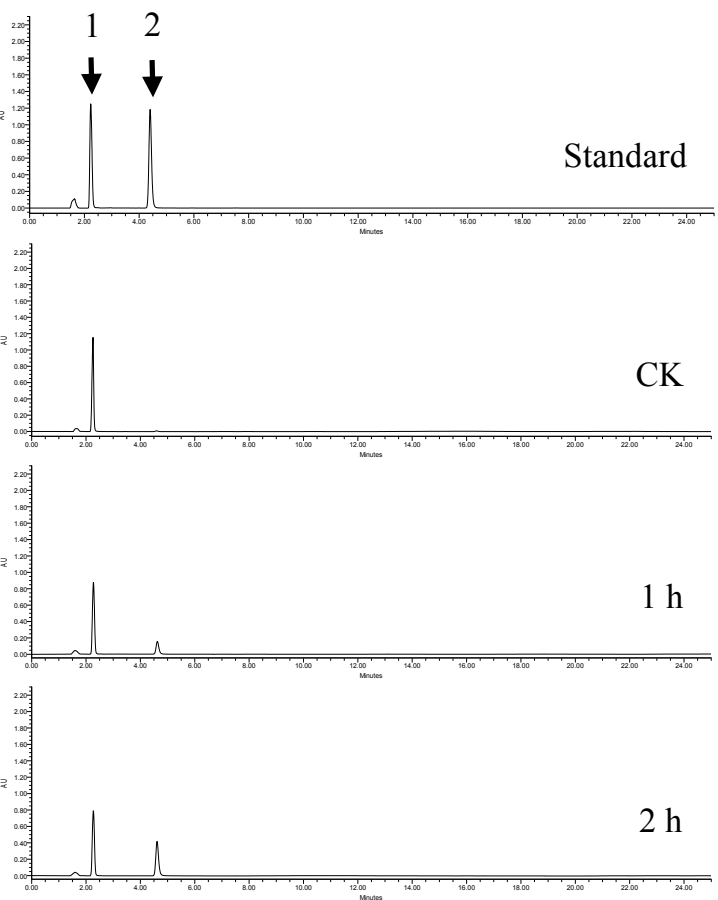

$3 \mathrm{~h}$

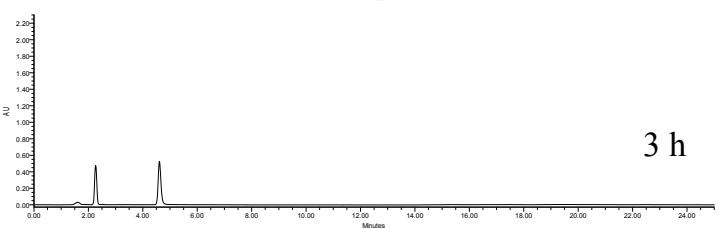

$4 \mathrm{~h}$

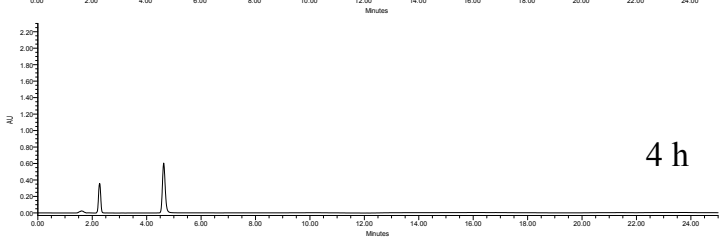

$6 \mathrm{~h}$

Figure 10. High-performance liquid chromatograms of the reaction solution from different time points in the biphase conversion system (A) and the uniphase conversion system (B). Standard, (1) polydatin; (2) resveratrol. CK, reactions without enzyme; $1-6 \mathrm{~h}$, different time points after the enzyme action.

\subsection{Optimization of Biphase Enzymatic Conversion System}

Based on the results described above, the biphase conversion system was chosen for further study. To investigate the optimal final concentration of polydatin extract $(20 \%$ purity), reactions containing 20,30, 40 and $50 \mathrm{~g} / \mathrm{L}$ of crude polydatin were carried out at $40{ }^{\circ} \mathrm{C}$ and $\mathrm{pH}$ 6.0. As shown in Figure 11, a high conversion ratio was observed in the reactions containing 20 and $30 \mathrm{~g} / \mathrm{L}$ substrate. To maximize resveratrol production, $30 \mathrm{~g} / \mathrm{L}$ was chosen as the optimum substrate concentration. 


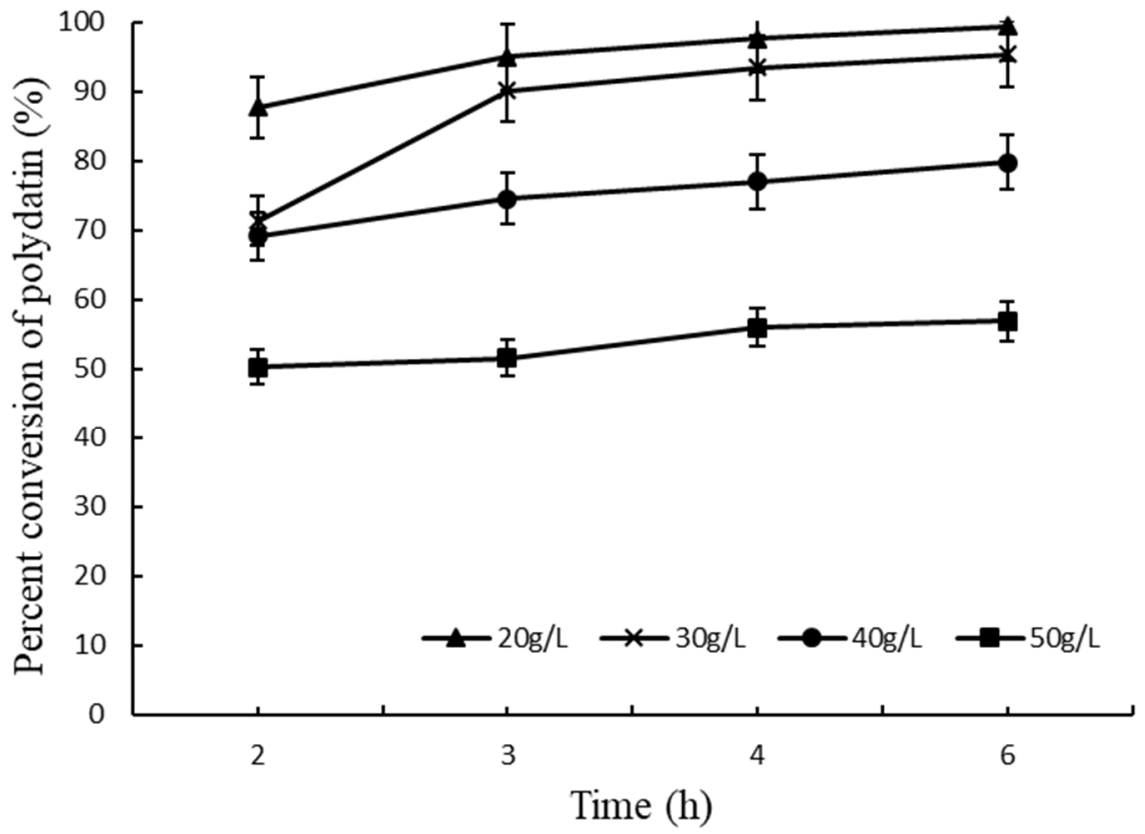

Figure 11. Effect of polydatin concentration on the conversion ratio. Crude polydatin (20\% purity) was added to the reaction to final concentrations of 20,30, 40 and $50 \mathrm{~g} / \mathrm{L}$.

The ability of SpBGL1 to convert crude polydatin (20\% purity) to resveratrol in the optimum conditions was determined. As shown in Figure 12, after $1 \mathrm{~h}, 71.25 \%$ of the substrate was hydrolyzed, and after $4 \mathrm{~h}$ the substrate was almost completely hydrolyzed (95.3\%). The deduced resulting concentration of resveratrol was $3.34 \mathrm{~g} / \mathrm{L}$.

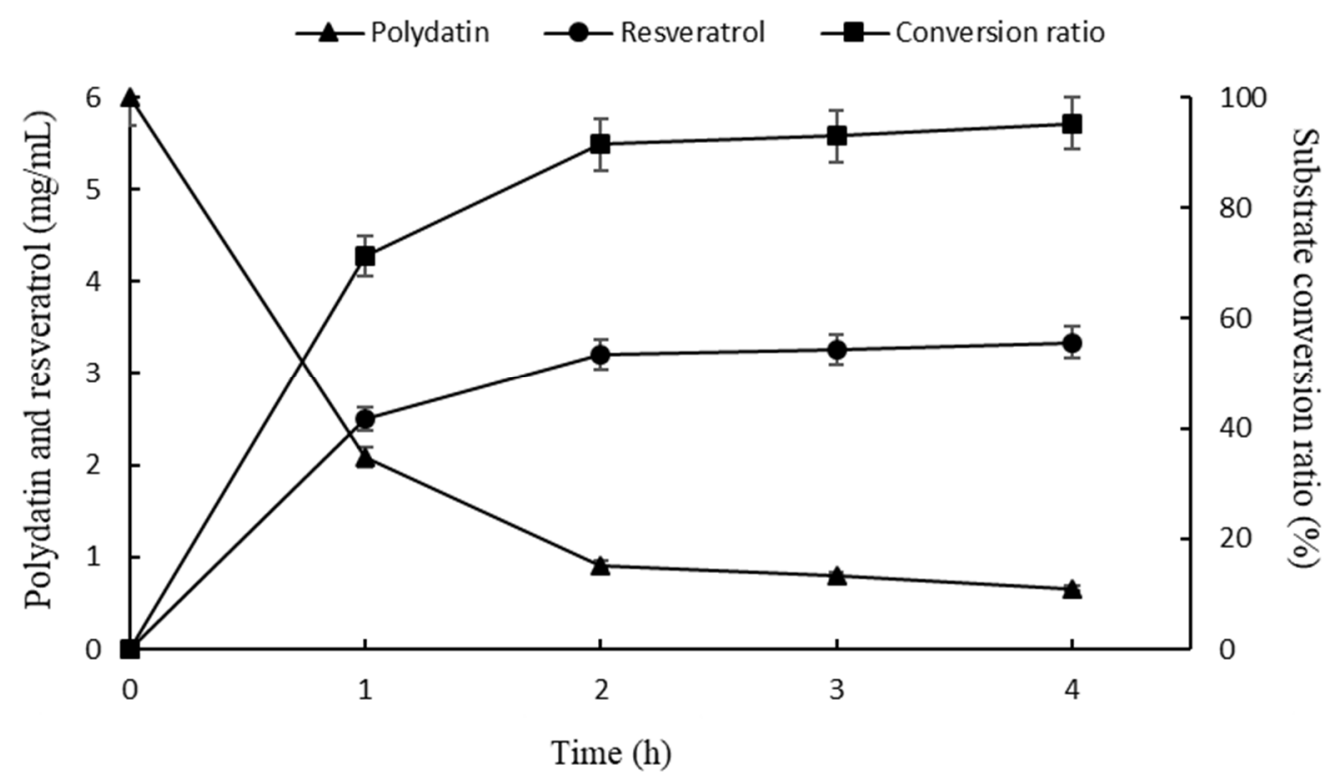

Figure 12. Time course of enzymatic transformation of crude polydatin and the deduced production of resveratrol. Each value in the figure represents the mean \pm standard deviation $(n=3)$.

\section{Discussion}

Bioconversion of polydatin to resveratrol is advantageous compared with other conversion methods, such as acid hydrolysis, in terms of energy consumption, complexity and resulting pollution. Microbial conversion was once the most widely used method for bioconversion of polydatin [28]. However, the main drawback of this method is that 
the culture conditions of the microorganisms, such as temperature and $\mathrm{pH}$, are different from those for the optimal function of the enzyme. Second, the fermentation generally requires a relatively long time to achieve a high conversion ratio. Hence, enzymatic conversion of polydatin to resveratrol could be more efficient. Unfortunately, however, few enzymes suitable for efficient industrial conversion of polydatin to resveratrol have been reported. Generally, $\beta$-D-glucosidases from bacteria are less efficient than those originating from fungi, such as the piceid- $\beta$-D-glucosidase purified from $A$. oryzae sp. 100, which can convert $90 \%$ of polydatin to resveratrol in $4 \mathrm{~h}$ [27]. In the work of $\mathrm{Hu}$ et al., [17] several glucosidases from Bacillus safensis were studied in conversion of polydatin to resveratrol; only two showed outstanding activity toward polydatin, and the best converted $93.1 \%$ of the resveratrol in $8 \mathrm{~h}$ when the substrate concentration was between $0.1 \%$ and $0.3 \%$.

In this study, we cloned and characterized a GH3 family $\beta$-D-glucosidase, SpBGL1, from Sphingomonas sp. ATCC31555. In previous work, we found that the enzymes derived from the Novosphingobium sp strain had special action on polyphenol glycoside substrates [29]. We hypothesized that there are similar enzymes in these related strains. These enzymes differ from other glycoside hydrolases in that they have the ability to act on glycoside compounds with aromatic aglycone. Indeed, SpBGL1 shows the ability to achieve that. This enzyme showed preferable characteristics for efficient conversion of polydatin into resveratrol. By applying SpBGL1 in a biphasic conversion system, the conversion ratio of $20 \%$ concentration crude polydatin to resveratrol reached $95.3 \%$ in $4 \mathrm{~h}$.

Polydatin and resveratrol are both poorly soluble in water; thus, microbial and enzymatic conversions generally require a secondary extraction step to recover the resveratrol. In this study, a minimized biphasic enzymatic transformation system was set up to overcome this drawback. Polydatin is poorly water-soluble, unable to dissolve at $20 \%$, but can be enzymatically hydrolyzed in this system. Resveratrol produced during the course of the conversion continuously dissolved in the organic phase, which allowed recovery of the product by simply removing the organic phase and vacuum evaporation. This procedure is less laborious and more effective compared to the extraction procedures that are usually required in uniphase conversion systems. As described by Huang et al., [30] the resveratrol produced in the uniphase system requires organic solvent recovery followed by sonication and multiple suction filtration steps to remove impurities before the final product precipitation and vacuum evaporation.

Raw extracts of polydatin were used as the substrate to test the efficiency of the system. The conversion ratio of polydatin by SpBGL1, 95.3\% in $4 \mathrm{~h}$, was comparable to that obtained in the conventional conversion system while obtaining resveratrol with high purity without the need for extra organic solvent extractions. The system is capable of decreasing the pretreatment of the raw material, lowering the requirement for crude substrate purity while maintaining the overall conversion efficiency. Since, generally, a large reaction volume is preferable for enzymatic conversions, SpBGL1 shows huge potential for industrial resveratrol production. Other than the application in polydatin conversion as reported in this study, the minimized biphasic enzymatic transformation system set up here could be applied to small-scale enzymatic reactions of other raw materials that have poor water solubility, which is often the case for raw materials in Chinese medicine.

\section{Materials and Methods}

\subsection{Bacterial Strains and Growth Conditions}

Sphingomonas sp. ATCC 31555 was purchased from the American Type Culture Collection (ATCC). Strain ATCC31555 was grown in YPG medium (5 g of tryptone, $3 \mathrm{~g}$ of yeast extract and $20 \mathrm{~g}$ of glucose per liter of $\mathrm{H}_{2} \mathrm{O}$ ) at $37^{\circ} \mathrm{C}$ in a shaker at $200 \mathrm{rpm}$. All Escherichia coli strains were cultured in LB medium (10 $\mathrm{g}$ of tryptone, $5 \mathrm{~g}$ of yeast extract and $10 \mathrm{~g}$ of $\mathrm{NaCl}$ per liter of $\mathrm{H}_{2} \mathrm{O}$ ) at $37^{\circ} \mathrm{C}$. 


\subsection{Cloning of SpBGL1}

The open reading frame encoding SpBGL1 (accession number: WP_019370396.1) was amplified using primers 96Fw (agcttcatgatgCAGACCCAGGCCGCCCGGGC) and 96Rev (agctaagcttAGTGGTGATGATGGTGATGTCGAACGGTGAGCGTGGC). The forward primer was designed to avoid amplifying the signal peptide and a start codon was added immediately upstream of the 29th amino acid. Motif analysis was performed using SMART (http:/ / smart.embl-heidelberg.de/, accessed on 10 January 2022). NcoI and HindIII restriction sites were included at the $5^{\prime}$ - end of the forward and reverse primers, respectively. The NcoI and HindIII-digested PCR product was ligated with pQE30 digested with the same enzymes, resulting in PQE-SpBGL1.The integrity of the cloned gene was verified by DNA sequencing.

\subsection{Heterologous Expression of SpBGL1}

pQE-SpBGL1 was transformed into E. coli strain JM109 by electroporation. The resulting transformants were verified using primers $96 \mathrm{Fw}$ and $96 \mathrm{Rev}$. To express the $\beta-$ glucosidase, a recombinant clone was pre-cultured overnight in $10 \mathrm{~mL}$ of LB medium, then $4 \mathrm{~mL}$ of the pre-culture were inoculated into $200 \mathrm{~mL}$ of LB medium supplemented with $100 \mathrm{mg} / \mathrm{mL}$ ampicillin and $0.5 \mathrm{mM}$ isopropyl $\beta$-D-1-thiogalactopyranoside. The culture was incubated at $20^{\circ} \mathrm{C}$ for $24 \mathrm{~h}$ in a shaker at $200 \mathrm{rpm}$.

The cells in $1 \mathrm{~L}$ of culture were collected by centrifugation at $8000 \mathrm{rpm}$ for $10 \mathrm{~min}$, then resuspended in $6 \mathrm{~mL}$ of $\mathrm{H}_{2} \mathrm{O}$ and lysed by sonication (JY92-2D, Xinzhi Ltd., Ningbo, China). The cell-free lysate was loaded onto a Ni-NTA column (Qiagen, Venlo, The Netherlands). The column was washed once with $4 \mathrm{~mL}$ of wash buffer $\left(\mathrm{NaH}_{2} \mathrm{PO}_{4}, 50 \mathrm{mM} ; \mathrm{NaCl}, 300 \mathrm{mM}\right.$; imidazole, $20 \mathrm{mM} ; \mathrm{pH} 8.0$ ), then the $\beta$-glucosidase was eluted with $2 \mathrm{~mL}$ of elution buffer $\left(\mathrm{NaH}_{2} \mathrm{PO}_{4}, 50 \mathrm{mM} ; \mathrm{NaCl}, 300 \mathrm{mM}\right.$; imidazole, $250 \mathrm{mM} ; \mathrm{pH}$ 8.0). The purified protein was confirmed by SDS-PAGE.

\subsection{Enzyme Activity Assays}

The activity of the purified $\beta$-glucosidase was assayed using $p$ NPG as the substrate. Briefly, $10 \mu \mathrm{L}$ of the enzyme were mixed with $20 \mu \mathrm{L}$ of $p$ NPG in $170 \mu \mathrm{L}$ of McIlvaine buffer. The mixtures were incubated at the desired temperature for $20 \mathrm{~min}$, then the reactions were terminated using $1 \mathrm{M} \mathrm{Na}_{2} \mathrm{CO}_{3}$. The absorbance of the mixture was measured at $405 \mathrm{~nm}$. Each reaction was performed independently three times.

Product inhibition assays were carried out as described above except glucose $(0.5-3 \mathrm{M}$, $0.5 \mathrm{M}$ interval) was added to the reaction; these reactions were carried out at the optimum temperature and $\mathrm{pH}$.

Organic solvent tolerance was tested in reactions containing ethanol or methanol $(5-30 \%, v / v)$. Chemical compound tolerance was tested by adding Triton X-100 (1\%), $\beta$-mercaptoethanol $(1 \%)$, Tween $80(5 \%)$ or imidazole $(10 \mathrm{mM})$ to the reaction. All reactions were carried out at the optimum temperature and $\mathrm{pH}$ as described above, and the relative activities were calculated using the activity of SpBGL1 in additive-free reaction buffer as a reference.

\subsection{Enzymatic Characterization of SpBGL1}

The optimum $\mathrm{pH}$ of SpBGL1 with $p$ NPG as the substrate was determined at $37^{\circ} \mathrm{C}$. SpBGL1 $(10 \mu \mathrm{L})$ was mixed with $20 \mu \mathrm{L}$ of substrate $(2 \mathrm{mM})$ in the following buffers: $100 \mathrm{mM}$ glycine- $\mathrm{HCl}$ for $\mathrm{pH} 2.0-3.0$, Mcllvaine buffer for $\mathrm{pH} 3.0-8.0,100 \mathrm{mM}$ Tris- $\mathrm{HCl}$ for $\mathrm{pH} 8.0-9.0$ and $100 \mathrm{mM}$ glycine- $\mathrm{NaOH}$ for $\mathrm{pH} 9.0-12.0$. The volume of the mixtures was adjusted to $200 \mu \mathrm{L}$, they were incubated at $37^{\circ} \mathrm{C}$ for $20 \mathrm{~min}$ and the absorbance was measured as described in Section 4.4.

The optimum temperature for the enzyme activity was measured at the optimum $\mathrm{pH}$ by measuring the enzymatic activity at $20,25,30,35,40,45,50,55$ and $60{ }^{\circ} \mathrm{C}$.

$\mathrm{K}_{\mathrm{m}}$ and $\mathrm{V}_{\mathrm{max}}$ values of SpBGL1 were determined at the optimum reaction temperature in Mcllvaine buffer (at the optimum $\mathrm{pH}$ ) containing 0.1-20 mM $p$ NPG. The experiment was 
triplicated, and the values were calculated using the Lineweaver-Burk method and GraFit software (version GraphPad Prism 5, Erithacus Software, Horley, UK). The $K_{i}$ value was calculated using the SNLR (simultaneous nonlinear regression fit) method [31].

\subsection{Optimal Enzymatic Conditions for Catalysis of Polydatin by SpBGL1}

The optimal $\mathrm{pH}$ for catalysis of polydatin by SpBGL1 was determined as described in Section 4.5 , except that $20 \mu \mathrm{L}$ of polydatin $(100 \mu \mathrm{g} / \mathrm{mL})$ were used as the substrate and the $\mathrm{pH}$ value was adjusted to 4.5-7.0. The optimal temperature for the reaction was determined as described in Section 4.5, except the temperature was set to 35 to $60{ }^{\circ} \mathrm{C}$ (at $5{ }^{\circ} \mathrm{C}$ intervals).

HPLC was performed using a Waters ALLIANCE E2695 HPLC system (Milford, MA, USA) equipped with a C18 column. The isocratic elution of polydatin and resveratrol was carried out using acetonitrile (35\%) at a flow rate of $0.8 \mathrm{~mL} / \mathrm{min}$. Polydatin and its hydrolysis products were detected at $303 \mathrm{~nm}$. Calibration curves were established to determine the concentrations of polydatin and resveratrol. Briefly, standard solutions of polydatin (1, 2, 3, 4, 5 and $10 \mathrm{~g} / \mathrm{L})$ and resveratrol $(1,2,3,4,5$ and $10 \mathrm{~g} / \mathrm{L})$ were subjected to HPLC analysis and the corresponding peak area was plotted against the concentration of the standard solution using Microsoft Excel.

\subsection{Enzymatic Hydrolysis Assay in The Uniphase and Biphasic Conversion Systems}

Uniphase and biphasic transformation systems were set up to compare their effectiveness in converting polydatin into resveratrol. The biphasic enzymatic hydrolysis system was established as described by Shen et al. [32] with modifications adapted to our sample and purpose: first, the system contained $3 \mathrm{~mL}$ of aqueous phase (McIlvaine buffer, $\mathrm{pH}$ 6.0) and organic phase (ethyl acetate) each; second, SpBGL1 was added to the aqueous phase and the desired amount of crude polydatin was added to the aqueous phase. At each sampling time point, organic phase solution was carefully removed for vacuum concentration. The resulting powder was dissolved in $80 \%$ methanol and subjected to HPLC analysis for the quantification of resveratrol. The uniphase system was composed of $3 \mathrm{~mL}$ of McIlvaine buffer ( $\mathrm{pH}$ 6.0). In both systems, crude polydatin (20\% purity) was added into the reaction without preheating to increase the solubility (in form of precipitation), the final concentration of SpBGL1 was $180 \mu \mathrm{g} / \mathrm{mL}$ and the reactions were conducted at $40{ }^{\circ} \mathrm{C}$. Recovery of resveratrol from the uniphase conversion system was carried out according to Huang et al., except that methanol was used to recover the resveratrol before vacuum concentration [30].

\section{Conclusions}

To efficiently convert polydatin to resveratrol, GH3 family $\beta$-D-glucosidase SpBGL1 was selected and characterized. This enzyme can effectively convert polydatin to resveratrol and has good tolerance toward organic solvents. By use of this enzyme in a biphasic system, $95.3 \%$ conversion of polydatin to resveratrol was achieved and high-purity resveratrol was obtained without additional organic solvent extraction.

Author Contributions: Conceptualization, H.P. and L.D.; investigation, J.Z., M.L. and Y.L.; writingoriginal draft preparation, J.Z.; writing—review and editing, H.P. and L.D.; supervision, R.H.; project administration, Y.W.; funding acquisition, L.D. All authors have read and agreed to the published version of the manuscript.

Funding: This research was funded by the Natural Science Foundation of China (31360369), The Guangxi Science and Technology Major Project (AA19254025, AB17190534) and The Guangxi Chairman Technology Fund (17290-03).

Institutional Review Board Statement: Not applicable.

Informed Consent Statement: Not applicable.

Data Availability Statement: All the data supporting the findings of this study are included in this article. 
Conflicts of Interest: The authors declare no conflict of interest.

Sample Availability: Samples of the compounds are available from the authors.

\section{References}

1. Jeandet, P.; Delaunois, B.; Conreux, A.; Donnez, D.; Nuzzo, V.; Cordelier, S.; Clement, C.; Courot, E. Biosynthesis, metabolism, molecular engineering and biological functions of stilbene phytoalexins in plants. Biofactors 2010, 36, 331-341. [CrossRef]

2. Jeandet, P.; Douillt-Breuil, A.C.; Bessis, R.; Debord, S.; Sbaghi, M.; Adrian, M. Phytoalexins from the vitaceae: Biosynthesis, phytoalexin gene expression in transgenic plants, antifungal activity, and metabolism. J. Agric. Food Chem. 2002, 50, $2731-2741$. [CrossRef]

3. Jeandet, P.; Clément, C.; Courot, E. Use of plant cell suspensions as a basis for large-scale production of resveratrol in bioreactors. Eng. Life Sci. 2014, 14, 622-632. [CrossRef]

4. Coutinho, D.D.; Pacheco, M.T.; Frozza, R.L.; Bernardi, A. Anti-Inflammatory Effects of Resveratrol: Mechanistic Insights. Int. J. Mol. Sci. 2018, 19, 1812. [CrossRef]

5. Shen, C.Y.; Jiang, J.G.; Yang, L.; Wang, D.W.; Zhu, W. Anti-ageing active ingredients from herbs and nutraceuticals used in traditional Chinese medicine: Pharmacological mechanisms and implications for drug discovery. Br. J. Pharmacol. 2017, 174, 1395-1425. [CrossRef]

6. Voloshyna, I.; Hussaini, S.M.; Reiss, A.B. Resveratrol in Cholesterol Metabolism and Atherosclerosis. J. Med. Food 2012, 15, 763-773. [CrossRef]

7. Gambini, J.; Inglés, M.; Olaso, G.; Lopez-Grueso, R.; Bonet-Costa, V.; Gimeno-Mallench, L.; Mas-Bargues, C.; Abdelaziz, K.M.; Gomez-Cabrera, M.C.; Vina, J.; et al. Properties of Resveratrol: In Vitro and In Vivo Studies about Metabolism, Bioavailability, and Biological Effects in Animal Models and Humans. Oxid. Med. Cell. Longev. 2015, 2015, 837042. [CrossRef]

8. Jeandet, P.; Bessis, R.; Gautheron, B. The production of resveratrol (3,5,4'-trihydroxystilbene) by grape berries in different developmental stages. Am. J. Enol. Vitic. 1991, 42, 41-46.

9. $\quad$ Lyons, M.M.; Yu, C.W.; Toma, R.B.; Cho, S.Y.; Reiboldt, W.; Lee, J.; Van Breemen, R.B. Resveratrol in raw and baked blueberries and bilberries. J. Agric. Food Chem. 2003, 51, 5867-5870. [CrossRef]

10. Mudnic, I.; Budimir, D.; Modun, D.; Gunjaca, G.; Generalic, I.; Skroza, D.; Katalinic, V.; Ljubenkov, I.; Boban, M. Antioxidant and Vasodilatory Effects of Blackberry and Grape Wines. J. Med. Food 2012, 15, 315-321. [CrossRef]

11. Shrikanta, A.; Kumar, A.; Govindaswamy, V. Resveratrol content and antioxidant properties of underutilized fruits. J. Food Sci. Technol. 2015, 52, 383-390. [CrossRef]

12. Wang, Y.; Catana, F.; Yang, Y.N.; Roderick, R.; van Breemen, R.B. An LC-MS method for analyzing total resveratrol in grape juice, cranberry juice, and in wine. J. Agric. Food Chem. 2002, 50, 431-435. [CrossRef]

13. Nonomura, S.; Kanagawa, H.; Makimoto, A. Chemical constituents of polygonaceous plants. I. Studies on the components of Ko-jo-kon (Polygonum cuspidatum Sieb Et Zucc.). Yakugaku Zasshi 1963, 83, 988-990. [CrossRef]

14. Henry, C.; Vitrac, X.; Decendit, A.; Ennamany, R.; Krisa, S.; Mérillon, J.-M. Cellular Uptake and Efflux of trans-Piceid and Its Aglycone trans-Resveratrol on the Apical Membrane of Human Intestinal Caco-2 Cells. J. Agric. Food Chem. 2005, 53, 798-803. [CrossRef]

15. Signorelli, P.; Ghidoni, R. Resveratrol as an anticancer nutrient: Molecular basis, open questions and promises. J. Nutr. Biochem. 2005, 16, 449-466. [CrossRef]

16. Wang, C.; Liu, X.; Zhang, M.; Shao, H.; Wang, X.; Wang, Q.; Bao, Z.; Fan, X.; Li, H. Efficient Enzyme-Assisted Extraction and Conversion of Polydatin to Resveratrol From Polygonum cuspidatum Using Thermostable Cellulase and Immobilized $\beta$-Glucosidase. Front. Microbiol. 2019, 10, 445. [CrossRef]

17. Hu, X.; Liu, Y.; Li, D.; Feng, W.; Ni, H.; Cao, S.; Lu, F.; Li, Y. An innovative biotransformation to produce resveratrol by Bacillus safensis. RSC Adv. 2019, 9, 15448-15456. [CrossRef]

18. Che, J.; Shi, J.; Gao, Z.; Zhang, Y. A New Approach to Produce Resveratrol by Enzymatic Bioconversion. J. Microbiol. Biotechnol. 2016, 26, 1348-1357. [CrossRef]

19. Wang, D.-G.; Liu, W.-Y.; Chen, G.-T. A simple method for the isolation and purification of resveratrol from Polygonum cuspidatum. J. Pharm. Anal. 2013, 3, 241-247. [CrossRef]

20. Zada, N.S.; Belduz, A.O.; Güler, H.I.; Sahinkaya, M.; Khan, S.I.; Saba, M.; Bektas, K.I.; Kara, Y.; Kolayll, S.; Badshah, M.; et al. Cloning, biochemical characterization and molecular docking of novel thermostable $\beta$-glucosidase BglA9 from Anoxybacillus ayderensis A9 and its application in de-glycosylation of Polydatin. Int. J. Biol. Macromol. 2021, 193, 1898-1909. [CrossRef]

21. Wang, J.-D.; Fu, L.-N.; Wang, L.-T.; Cai, Z.-H.; Wang, Y.-Q.; Yang, Q.; Fu, Y.-J. Simultaneous transformation and extraction of resveratrol from Polygonum cuspidatum using acidic natural deep eutectic solvent. Ind. Crops Prod. 2021, 173, 114140. [CrossRef]

22. Wang, H.; Liu, L.; Guo, Y.X.; Dong, Y.S.; Zhang, D.J.; Xiu, Z.L. Biotransformation of piceid in Polygonum cuspidatum to resveratrol by Aspergillus oryzae. Appl. Microbiol. Biotechnol. 2007, 75, 763-768. [CrossRef] [PubMed]

23. Tian, T.L.; Sun, Q.L.; Shen, J.; Zhang, T.; Gao, P.; Sun, Q. Microbial transformation of polydatin and emodin-8-beta-D-glucoside of Polygonum cuspidatum Sieb. et Zucc into resveratrol and emodin respectively by Rhizopus microsporus. World J. Microbiol. Biotechnol. 2008, 24, 861-866. [CrossRef] 
24. Xu, N.E.; Luo, L.B.; Mei, J.F.; Jia, Y.Q.; Wang, Q.Z. Increasing the Content of Resveratrol in Chinese Herb Polygonum Cuspidatum by Bioconversion. Pharm. Biotechnol. 2012, 19,3.

25. Wan, H.-D.; Tao, G.-J.; Kim, D.; Xia, Y.-M. Enzymatic preparation of a natural sweetener rubusoside from specific hydrolysis of stevioside with $\beta$-galactosidase from Aspergillus sp. J. Mol. Catal. B Enzym. 2012, 82, 12-17. [CrossRef]

26. Nguyen, T.T.; Jung, S.J.; Kang, H.K.; Kim, Y.M.; Moon, Y.H.; Kim, M.; Kim, D. Production of rubusoside from stevioside by using a thermostable lactase from Thermus thermophilus and solubility enhancement of liquiritin and teniposide. Enzym. Microb. Technol. 2014, 64-65, 38-43. [CrossRef]

27. Chen, M.; Li, D.; Gao, Z.Q.; Zhang, C.Z. Enzymatic transformation of polydatin to resveratrol by piceid-beta-d-glucosidase from Aspergillus oryzae. Bioprocess Biosyst. Eng. 2014, 37, 1411-1416. [CrossRef]

28. Liu, J.; Zhang, X.; Yan, T.; Wang, F.; Li, J.; Jia, L.; Jia, J.; Hu, G. Screening of an Endophyte Transforming Polydatin to Resveratrol from Reynoutria Japonica Houtt and the Optimization of Its Transformation Parameters. Molecules 2020, 25, 4830. [CrossRef]

29. Du, L.; Wang, Z.; Zhao, Y.; Huang, J.; Pang, H.; Wei, Y.; Lin, L.; Huang, R. A ß-glucosidase from Novosphingobium sp. GX9 with high catalytic efficiency toward isoflavonoid glycoside hydrolysis and (+)-catechin transglycosylation. Appl. Microbiol. Biotechnol. 2014, 98, 7069-7079. [CrossRef]

30. Huang, Z.F.; Yi, J.H.; Liu, Q.L.; Liu, Y.H.; Chen, Y.; Liu, Y.H. Rearch of Extracting and Purifying Process of Resveratrol from Polygonum caspidatum Extract by Enzymatic Hydrolysis. Nat. Prod. Res. Dev. 2009, 21, 1061-1064.

31. Kakkar, T.; Boxenbaum, H.; Mayersohn, M. Estimation of Ki in a Competitive Enzyme-Inhibition Model: Comparisons Among Three Methods of Data Analysis. Drug Metab. Dispos. 1999, 27, 756. [PubMed]

32. Shen, Y.; Wang, H.; Lu, Y.; Xu, L.; Yin, H.; Tam, J.P.; Yang, H.; Jia, X. Construction of a novel catalysis system for clean and efficient preparation of Baohuoside I from Icariin based on biphase enzymatic hydrolysis. J. Clean. Prod. 2018, 170, 727-734. [CrossRef] 